\title{
Programas de geometria no ensino primário paulista: do império à primeira república ${ }^{1}$
}

\author{
Maria Célia Leme da Silva* \\ Wagner Rodrigues Valente**
}

\begin{abstract}
Resumo
O presente artigo intenta contribuir para o preenchimento de uma lacuna presente na história da educação matemática: investigar o ensino de geometria no curso primário do final do século XIX ao início do século XX. Caminhando pelas normas legislativas da educação, focadas no Estado de São Paulo, a pesquisa analisa os programas propostos para a matéria de geometria, assim como as discussões acerca da metodologia de ensino desse saber. Pode-se dizer que a Reforma da Instrução Pública de 1892 consolida a entrada da geometria como matéria a compor o programa com a denominação de Geometria prática. Seu significado relaciona os conceitos geométricos com objetos da vida prática e inclui nessa praticidade as construções geométricas com régua e compasso. Com o referencial do pesquisador André Chervel os resultados constituem subsídios para a investigação acerca da finalidade teórica de uma "geometria prática" em confronto com as finalidades reais da disciplina Geometria.

Palavras-chave: Ensino de geometria; Ensino primário; História da educação matemática.
\end{abstract}

\section{Geometry programs in primary education paulista: empire until first republic}

\begin{abstract}
This article intends to contribute to filling a gap in the history of mathematics education: investigating the teaching of geometry in elementary school the late nineteenth century to the early twentieth century. Walking through the legislative standards of education, focused on the state of São Paulo, the research analyzes the programs proposed for the field of geometry, as well as discussions about the teaching methodology of this knowledge. You could say that the Reform of Public Instruction, 1892 consolidates the input geometry as matter composing the program with the name of Geometry practice. Its significance relates geometrical concepts with objects of everyday life and that includes practical geometric constructions with ruler and compass. With the reference of researcher Andrew Chervel the results provide grants for research on the theoretical purpose of a "practical geometry" in comparison with the real purposes of discipline Geometry.
\end{abstract}

Keywords: Teaching Geometry; Primary education; History of mathematics education.

\section{Considerações Iniciais}

O presente artigo objetiva contribuir para o preenchimento de uma lacuna presente na história da educação matemática: investigar o ensino de geometria no curso primário do final do século XIX ao início do século XX. A historiadora Rosa Fátima de Souza apresenta, em recente publicação, uma vasta revisão das pesquisas desenvolvidas sobre a história do ensino primário no Estado de São Paulo $(1890-1976)^{2}$ e destaca a necessidade de investigações envolvendo a história de cada uma das matérias do programa da escola primária. No que diz respeito às matemáticas, e mais especificamente à geometria, ainda são raros estudos mais aprofundados que abordem como se deu o ensino dessa matéria nas escolas primárias e no período em questão.

Assim sendo, apresentamos resultados de uma investigação maior, que tem como meta traçar a trajetória do processo de escolarização da

* Endereço eletrônico: celia.leme@ unifesp.br

** Endereço eletrônico: wagner.valente@ unifesp.br geometria nas escolas primárias. Caminhando pelas normas legislativas da educação desde o período do Império até as primeiras décadas da República, focadas no Estado de São Paulo, analisamos os programas propostos para a matéria de geometria, assim como as discussões presentes acerca da metodologia de ensino desse saber.

$\mathrm{O}$ estudo das normas que regem o ensino, segundo o historiador Dominique Julia (2001), é o mais tradicional da história da educação. Além disso, a legislação escolar constitui um corpus documental mais acessível para uma investigação inicial.

Outro ponto destacado por Julia, no uso das normas legislativas como fontes de pesquisa para estudo das finalidades do ensino é a escolha de tempos de crise e de conflitos, que se revelam mais profícuos para uma melhor compreensão do funcionamento real das finalidades atribuídas à escola. A reorganização do ensino primário paulista, com a constituição dos grupos escolares, nos 
primeiros anos após a Proclamação da República, configura-se como um desses momentos particulares.

\section{A geometria em tempos do Império}

A primeira lei sobre a instrução no Brasil após a Independência data de 15 de outubro de 1827 e no artigo $6^{\circ}$ determina que:

os Professores ensinarão a ler, escrever, as quatro operações de arithmetica, pratica de quebrados, decimaes e proporções, as noções mais geraes de geometria pratica, a grammatica da lingua nacional, $e$ os principios da moral christã e de doutrina de religião catholica e apostolica romana, proporcionados à comprehensão dos meninos; preferindo para as leitura a Constituição do Imperio e história do Brazil (COLLEÇÃO, 1827, grifo nosso).

Vê-se que o ensino primário brasileiro, logo em sua primeira lei, apresenta a necessidade do ensino das "noções gerais de geometria prática". Entretanto, a presença desse saber não se dá de forma absolutamente consensual. Muitos são os debates entre os parlamentares encontrados nos Anais da Câmara e do Senado, como relata Valente (2011). De um lado, os defensores do ensino da Geometria:

Não quero que o mestre ensine ou aponte o que é linha reta, quero que tome o compasso, descreva um triângulo sobre uma linha; isto não custa nada e é coisa mais fácil possível. Quero que o mestre prove o que ensina que os meninos aprendam como um carpinteiro ou pedreiro (MOACYR, p. 183 apud VALENTE, 2011, p. 7).

De outra parte, os contrários, alertam para possíveis dificuldades e problemas decorrentes de professores para lecionar a geometria:

Se exigirmos de um mestre de primeiras letras princípios de geometria elementar, dificultosamente se acharão; talvez apareçam muitos na Corte e nas províncias de beira-mar haja alguns; mas daí por diante haverá muito poucos ou nenhum (MOACYR, 1936, p. 183 apud VALENTE, 2011, p. 7).
Após muitos debates, os parlamentares que defendem a inclusão da geometria vencem e dessa forma, a geometria é inserida no rol de saberes a compor o ensino primário. O primeiro programa decretado pela Assembleia Geral Legislativa (Lei de 15 de outubro de 1827) se mantém nas escolas de ensino do município neutro (Corte) até 1854, quando se promulga uma reforma de instrução primária e secundária na capital do Império (MOACYR, 1936, p. 562).

O ensino público na Província de São Paulo, assim como em todo o país, tem pouco desenvolvimento na primeira metade do século XIX. A reforma realizada na Província em $1846^{3}$ fixa as matérias da escola de primeiras letras da seguinte forma:

Para o sexo masculino: leitura, escrita, teoria e prática da aritmética até proporções, inclusive as noções mais gerais de geometria prática, gramática da língua nacional e princípios da moral cristã e da doutrina da religião do Estado. Para as escolas do sexo feminino, as mesmas matérias executando a geometria $e$ limitação da aritmética à teoria e prática das quatro operações e prendas relacionadas à economia doméstica (Souza, 2009, p. 45, grifo nosso).

Mesmo que restrito ao sexo masculino, o ensino de geometria é apresentado, desde então, com a denominação geometria prática, seguindo orientações muito próximas as da Primeira Lei de 1827. Como não há maiores detalhes na legislação, pouco se pode compreender do significado desse saber presente na formação primária.

Cerca de trinta anos depois, em 1879, uma nova reformulação da instrução pública é oficializada pelo Decreto no. $7.247^{4}$ de 19 de abril de 1879, da Reforma do Ensino Primário e Secundário do Império. Nas disciplinas listadas no artigo $4^{\circ}$, para escolas primárias do $1^{\circ}$ grau $^{5}$ do município da Corte, consta, entre outras: princípios elementares de aritmética, sistema legal de pesos e medidas e elementos de desenho linear. Princípios elementares de álgebra e geometria é o nome de uma das disciplinas do rol do programa das escolas do $2^{\circ}$ grau $^{6}$.

Ao comparar as modificações de uma e outra regulamentação, há evidências de uma alteração. A disciplina - elementos de desenho linear - é introduzida como uma nova matéria e a 
disciplina - geometria - perde a qualificação de prática e restrita ao sexo masculino para ser apresentada como uma matéria do $2^{\circ}$ grau, destinada aos alunos maiores.

O Decreto de 1879, acima referido, assinado pelo ministro Leôncio de Carvalho, motiva inúmeros debates ao ser apreciado pelo Legislativo, resultando na elaboração de um parecer para subsidiar a discussão. Rui Barbosa é designado como relator dos pareceres ${ }^{7}$ apresentados ao parlamento brasileiro, no ano de 1882. Esse documento, conhecido como parecer de Rui Barbosa é considerado emblemático no processo de reforma do ensino primário e serve de referência para os republicanos nos debates e proposições sobre a educação popular no final do Império (Souza, 2009, p. 74).

E o que diz o parecer de Rui Barbosa no que concerne à geometria? Como ele se posiciona frente a essa questão? A grande defesa de Barbosa no seu substancioso parecer é o método intuitivo como condutor de toda a formação. Em relação à geometria, sua proposta de ensino ressalta:

É por meio de modelos materiais, de construções gráficas, que há de ter entrada na escola o curso sempre concreto, intuitivo, figurado dos elementos desta ciência. Começando por discernir ao aspecto as formas geométricas mais elementares, o sistema froebeliano adestrar utilmente o menino em reproduzi-las por meio de papelão, do papel, da terra plástica, ou do arame. Por uma graduada sucessão de passos, esta parte do programa, dominado e encaminhado sempre pelo mesmo espírito é susceptível do mais amplo desenvolvimento (Barbosa, 1947, p. 289-290).

Outro ponto de destaque sobre a geometria é a introdução, desde o $2^{\circ}$ grau da escola, da taquimetria, definida por ele como "concretização da geometria, é o ensino da geometria pela evidência material, a acomodação da geometria às inteligências mais rudimentares: é a lição de coisas aplicadas à medida das extensões e volumes" (Barbosa, 1947, p. 290).

As chamadas lições de coisas constituem a indicação metodológica proposta por Rui Barbosa para o ensino das ciências. Segundo Souza (2009), tinha a finalidade de extirpar a pedagogia retórica com base em nomes, datas, definições, preceitos.
Pressupunha o contato com os objetos e a observação.

Pode-se dizer que a proposta para o ensino de geometria, do ponto de vista da legislação, desde a metade do século XIX, assinala para uma geometria com aplicações práticas. Entretanto, vale destacar que, entre as finalidades propostas na legislação, e o que efetivamente é incorporado às práticas pedagógicas, há uma distância. Em termos da análise de André Chervel, distinguem-se as finalidades de objetivo e as finalidades reais. As primeiras, contidas no texto legislativo; as segundas, de fato praticadas no cotidiano das aulas.

\section{A geometria em tempos republicanos}

O ensino primário no Estado de São Paulo sofre várias reformas educacionais, logo após a Proclamação da República, em 1889. A Lei 88 de 18 de setembro de $1892^{8}$ estrutura o ensino público do Estado de São Paulo em três níveis assim denominados: ensino primário, ensino secundário e ensino superior. $\mathrm{O}$ ensino primário obrigatório para ambos os sexos, dos sete até a idade de 12 anos, compreende dois cursos: um preliminar e outro complementar.

Tanto a Lei 88 como o Decreto $144 \mathrm{~B}^{9}$ de 30 de dezembro de 1892 apresenta os programas do curso preliminar. No rol da das matérias, ambas as legislações trazem a chamada geometria prática (taquimetria) com as noções necessárias para as suas aplicações à medição de superfícies e volumes, sem maiores esclarecimentos.

É preciso ainda salientar o pioneirismo do Estado de São Paulo, na reunião de escolas isoladas num novo modelo de escola primária, denominada "grupo escolar", em 1893. Esse novo modelo simboliza a modernização do ensino e torna-se referência para os outros estados. Para além da nova organização física e administrativa do ensino primário nos grupos escolares, há também uma nova apresentação dos programas de ensino. Se antes, o controle do estado recaía apenas sobre o arcabouço estrutural do programa - o rol das matérias a serem ensinadas - a partir de então, prescrições cada vez mais detalhadas se voltam para a normatização das rotinas escolares. (Souza, 2009, p. 83-84).

Oscar Thompson, Benedito Tolosa e Antonio Rodrigues Alves ${ }^{10}$ elaboram o Programa para as matérias do curso preliminar em conformidade com a reforma de 1892. O Decreto 248 de 26 de junho de $1894^{11}$ oficializa o programa. 
Em termos do foco deste artigo, interessa saber: Como a geometria se apresenta nessa nova organização escolar?

Ao contrário de outras normatizações, o Decreto 248 traz um minucioso elenco de conteúdos para cada série e ano do curso preliminar. No $1^{\circ}$ ano do curso preliminar ${ }^{12}$, não há explicitamente a matéria geometria, entretanto identificamos muitos conceitos geométricos na matéria de desenho e de modelagem. A matéria geometria propriamente designada inicia na $1^{\text {a }}$ série do $2^{o}$ ano com os conceitos de: ponto, linha, superfície, sólido, linha reta, curva, quadrada, contínuas. Linhas de construção. Posição horizontal, vertical e oblíqua. Linhas retas combinadas: ângulo reto, agudo e obtuso. Figuras planas e retilíneas. Triângulo: retângulo, acutângulo, obtusângulo, equilátero, isósceles, escaleno. Quadriláteros: quadrados, diâmetros e diagonais. A grande quantidade de conteúdos em uma única série, como exemplificado acima, é uma característica que percorre o programa até o $4^{\circ}$ ano.

Outro aspecto dos conteúdos distribuídos na matéria de geometria é a presença de construção de figuras geométricas, com indicativo para uso de esquadro e régua, como na $1^{\mathrm{a}}$ série do $3^{\circ}$ ano, para a construção de triângulos isósceles, equiláteros e retângulos.

Quanto a aplicações de geometria, mais propriamente ao cálculo de áreas e volumes, esses conteúdos estão incluídos no $4^{\circ}$ ano, distribuídos em medida das superfícies e dos perímetros dos polígonos na $1^{a}$ série; e volume do cubo, prisma reto, obliquo, pirâmide, cilindro e esfera, na $2^{\mathrm{a}}$ série.

$\mathrm{O}$ estudo proposto para a matéria geometria contempla toda a geometria plana, com alguns elementos de geometria espacial, mais pontuais. As argumentações de Rui Barbosa de um ensino com modelos concretos são identificados na matéria modelagem, presente nos três primeiros anos do curso preliminar e que basicamente corresponde a modelar sólidos geométricos. Na geometria, não há menção de utilização de materiais e como já afirmamos, a geometria desenvolvida é predominantemente a geometria plana, enquanto a modelagem é feita através de objetos tridimensionais. Mesmo a chamada taquimetria, considerada a lição de coisas da geometria, é tratada timidamente e somente no último ano escolar. Tudo indica que, na geometria, as ideias defendidas por Barbosa não são contempladas na legislação de 1894.
Ainda no ano de 1894, é editado o livro "Primeiras Noções de Geometria Prática" de Olavo Freire. A edição de 1907 apresenta uma seção denominada "Algumas opiniões sobre a primeira edição", extraídas de jornais, como a que reproduzimos a seguir:

Jornal do Commercio, 29 de março de 1895:

Os Srs. Alves \& Cia acabão de editar um livro muito útil, do Sr. Olavo Freire. Intitula-se Primeiras noções de Geometria Prática e dá ao ensino de geometria elementar a facilidade que os estudantes não encontrão em outros compêndios. $\mathrm{O} \mathrm{Sr}$. Olavo Freire, pela clareza da sua exposição e pela excellencia do methodo que adoptou, soube tornar o seu livro uma obra didactica de mérito verdadeiramente excepcional. Por elle a geometria elementar póde ser ensinada com grande vantagem nas escolas de instrucção primária, e sabem todos quanto o conhecimento de geometria impõe-se hoje a todas as profissões (Freire, 1907, p. 9).

O livro de Freire é editado juntamente com o novo programa e traz, já no título, a sua marca: geometria prática. Se na legislação, não identificamos evidências de um programa que destaque o caráter prático da geometria, analisamos a obra em questão.

Trata-se de um livro de dimensão de $18 \mathrm{~cm}$ por $11 \mathrm{~cm}$, de capa dura, com 226 páginas, que incluem 490 exercícios, 92 problemas resolvidos e 381 gravuras, informações essas destacadas na capa do livro. Há ainda na capa, ao final, a frase "Approvada e premiada pelo Conselho de Instrucção Pública Federal". A geometria é distribuída em vinte e um capítulos, sendo os treze primeiros destinados ao estudo da geometria plana, finalizando com o cálculo de áreas de polígonos. Os demais capítulos reservados para a geometria espacial incluem também o cálculo de áreas e volumes dos poliedros e corpos redondos.

O primeiro capítulo do livro apresenta as definições de espaço, corpo, extensão, volume, superfície, linha e ponto. Observa-se que os conceitos são definidos sempre a partir de exemplos de objetos, com figuras ilustrativas, como as páginas da figura 1 a seguir: 


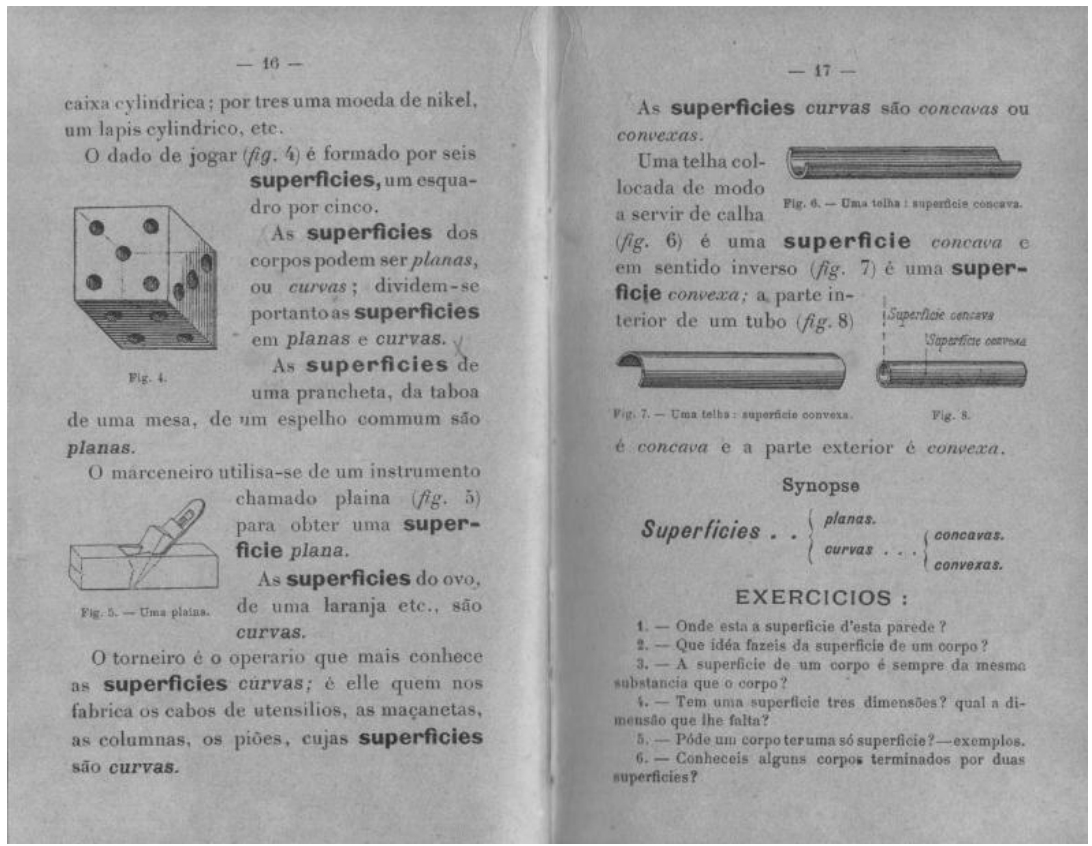

Figura 1 - Livro de Olavo Freire (páginas 16-17)

Ao analisar o capítulo I do livro, pode-se dizer que a geometria proposta tem um enfoque predominantemente prático, ao relacionar os conceitos apresentados com objetos e ferramentas da vida diária, destacando suas aplicações em algumas profissões, como se pode ver na figura 1, de marceneiro e torneiro. Vale ressaltar que nos demais capítulos esse enfoque é mantido, porém com uma frequência menor. No final do capítulo XVIII, intitulado corpos redondos, há uma nota: "Para as lições contidas nos capítulos XVI, XVII,
XVIII é necessário que o professor disponha de uma colleção de solidos geometricos. Estes sólidos devem ser feitos em cartão, pelos alumnos" (Freire, 1907, p. 179).

No capítulo II, é iniciado o estudo das construções geométricas com régua e compasso, que segue ao longo de todo o estudo de geometria plana. A figura 2 abaixo mostra o primeiro problema de construção realizado no livro, problema I, que se refere à construção de um ângulo igual a outro ângulo dado:

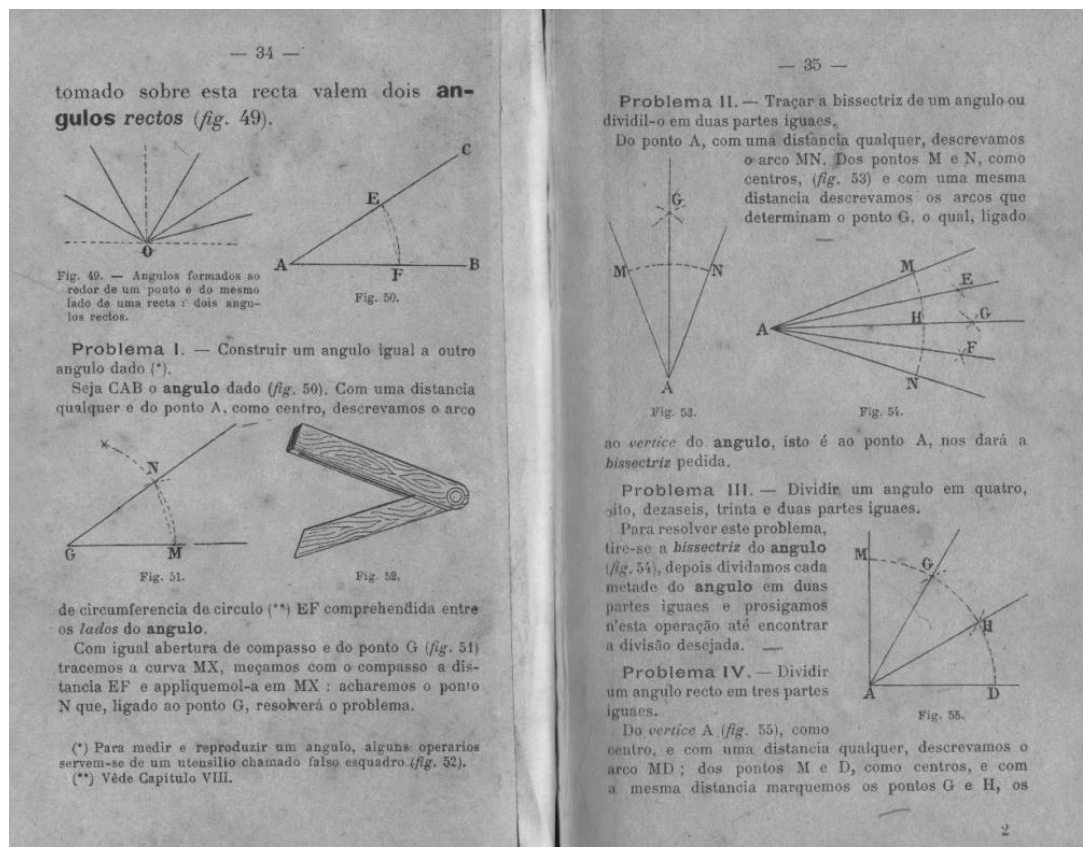

Figura 2 - Livro de Olavo Freire (páginas 34 e 35) 
As construções geométricas apresentadas nos demais capítulos seguem o mesmo padrão do problema I, ou seja, uma seqüência de passos a seguir até obter o objeto final construído. Não há explicação ou justificativa para que os procedimentos adotados na respectiva construção sejam os descritos. Ao todo, na obra, são apresentados 92 problemas, sendo a grande maioria de construções geométricas, alguns poucos, são destinados ao cálculo de áreas e volumes. No capítulo XXIII, são construídas as figuras: elipse, oval, espiral, hélice, parábola e hipérbole. O último problema, de número XCII, pede: "Traçar uma hyperbole com o compasso sendo dados os fócos $e$ os vértices" (Freire, 1907, p. 218).

Em relação ao cumprimento do programa apresentado no Decreto 248 de 1894, os conteúdos estabelecidos, praticamente todos eles, são tratados no livro de Freire, tanto a geometria plana como a espacial. Já em relação às construções geométricas, na legislação é feita somente uma menção na $1^{\text {a }}$ série do $3^{\circ}$ ano para a construção de triângulos isósceles, eqüilátero e retângulo, usando esquadro e régua, enquanto que no livro, todas as construções realizadas são desenvolvidas com régua e compasso, desde o capítulo II, percorrendo praticamente todos os conteúdos.

Resumidamente, a geometria proposta no livro de Freire, pode ser interpretada como uma geometria prática, na medida em que os conceitos estudados são relacionados com objetos da vida prática, porém a presença das construções geométricas de maneira contínua e crescente representa certa contradição ao enfoque prático. Se por um lado existe a praticidade na ação de construir objetos geométricos com régua e compasso, é preciso perguntar qual a finalidade de reproduzir esses passos, sem um entendimento dos procedimentos executados. Como teriam os alunos estudados essas construções? Como tais problemas são colocados na prática pedagógica? Como uma receita a ser decorada? Como explicar o caráter intuitivo em atividades dessa natureza?

As questões acima levantadas necessitam da análise de outras fontes para serem respondidas. Por enquanto, pode-se destacar o exemplo de uma prova de geometria da professora A. P. Ourique de Carvalho, do $3^{\circ}$ ano do Grupo Escolar Antonio Padilha, na cidade de Sorocaba, interior do estado de São Paulo, no ano de 1896, em que se pede o problema: "Traçar a bisectriz de um ângulo ou divid-o em duas partes iguaes"13. A aluna, da seção feminina, responde corretamente à questão da seguinte forma:

Suponhamos por exemplo o ângulo $A$ e do ponto A, com uma distancia qualquer, descrevemos a curva $M$ e N. Dos pontos $M$ $e$ P, como centros, e em uma mesma distancia descrevemos as curvas que determinam o ponto $G$, o qual ligado ao vértice do ângulo, isto é, ao ponto A nos dar a bisectriz pedida. (Souza, 2009, p. 94).

O problema cobrado na prova da aluna é exatamente o mesmo apresentado no livro de Olavo Freire, como problema II (figura 2). Há também outra prova de geometria, de um aluno do mesmo Grupo Escolar em que o problema é "Construir um triangulo sendo dados um lado e dois ângulos que lhe são adjacentes.", idêntico ao problema de número XVII do livro de Freire. Tais exemplos constituem indícios fortes de que a proposta para o ensino de geometria na escola primária efetivamente tenha chegado às salas de aulas, ao menos, na nova estruturação de ensino, nos grupos escolares paulistas. Fora isso, as duas provas apresentam na geometria, problemas de construções geométricas, para serem feitas com régua e compasso, o que apesar de não explicitado na legislação, é um traço marcante na obra de Freire.

Outra evidência da proposta da geometria prática de Freire ter feito escola no ensino primário é a longa vida da obra do autor. Ela atravessa a primeira metade do século XX, com muitas edições.

Outra fonte de pesquisa que permite uma leitura de como a legislação é interpretada nas práticas pedagógicas são as revistas de circulação entre professores primários. A Revista de Ensino ${ }^{14}$, dividida em seções, destina uma delas para a chamada Pedagogia Prática. A discussão sobre a matéria geometria é iniciada na revista número 3 , ano I, de agosto de 1902 e tem uma sequência de artigos, de mesma autoria, do professor Antonio Penna, até a revista número 1 , ano III, de abril de 1904.

Antonio Penna apresenta uma proposta para o ensino de geometria plana, dividida em um conjunto de 26 lições, nos respectivos anos escolares. Os artigos são exemplos de aulas, descrevem como o professor deve conduzir a classe na apresentação dos conceitos geométricos, faz perguntas aos alunos, pede que dirijam ao quadro negro, cria diálogos entre alunos e professores. $\mathrm{O}$ enfoque das aulas, assim como a do livro de Freire, é para a geometria prática, há muitos exemplos de 
objetos reais para representar os conteúdos da geometria. Novamente, encontramos as construções geométricas como uma das atividades propostas nas lições. No $1^{\mathrm{o}}$ ano do primário, na $7^{\mathrm{a}}$ lição - divisão da linha em duas, quatro, oito, etc partes eguaes - é apresentado o procedimento da construção com régua e compasso, conforme a figura 3 :

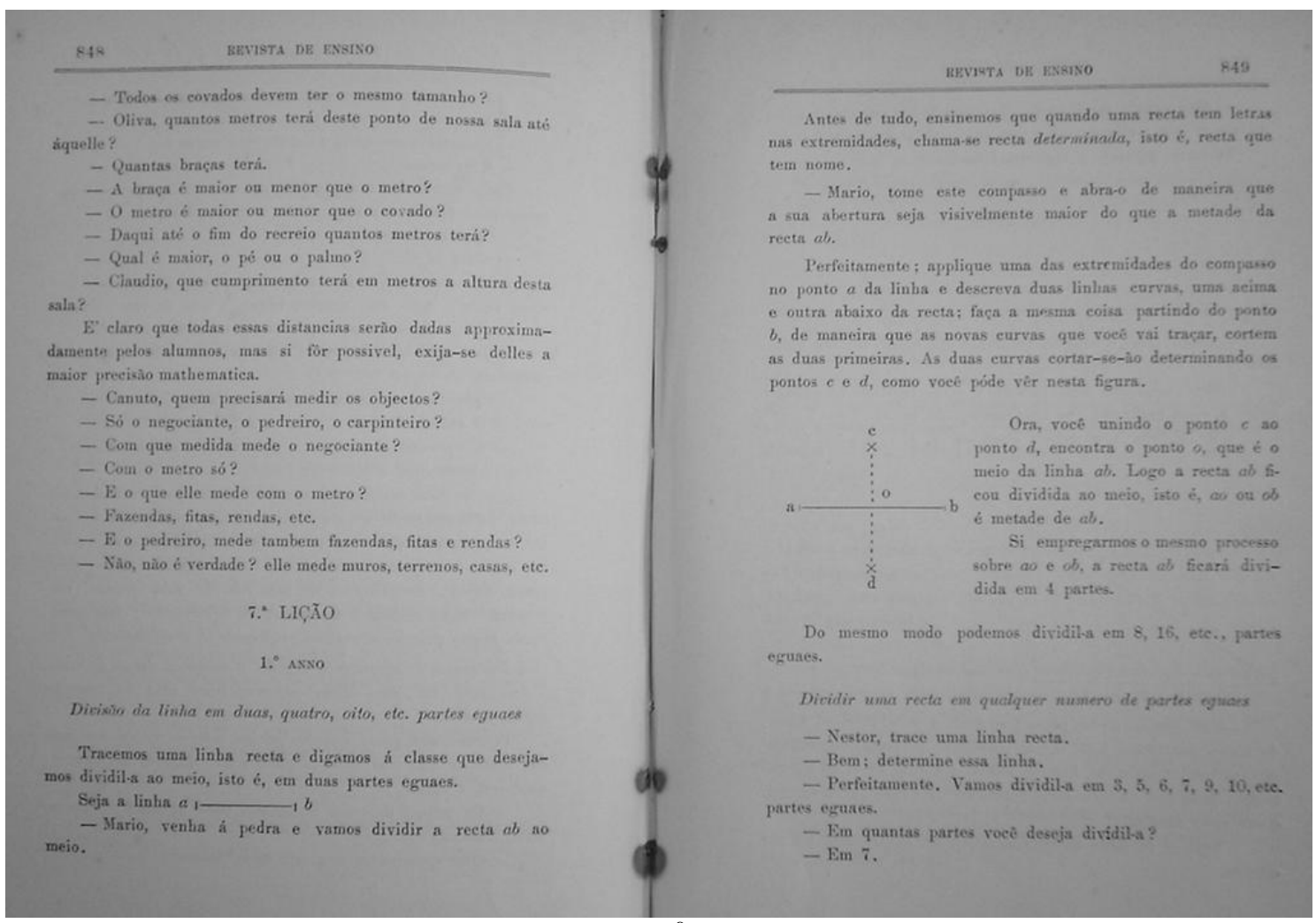

Figura 3 - Revista de Ensino (nº. 3, ano I, 1902, p. 848-849)

Apesar de uma linguagem diferente da utilizada por Freire, as construções são descritas passo a passo, sem que o aluno possa compreender o motivo da execução. Outro detalhe a ser destacado nas lições da Revista é a divisão das lições pelos anos escolares. A $7^{a}$ lição da figura 3 é a última lição destinada ao primeiro ano primário, ou seja, as construções geométricas com o uso do compasso são propostas para serem realizadas no $1^{\circ}$ ano do ensino primário.

Caminhando em tempos da Primeira República nas reformulações dos programas dos Grupos Escolares Paulista, depois de 11 anos, o Decreto $1.281^{15}$ em 1905 oficializa a próxima reforma. O programa de geometria sofre significativas mudanças, entre elas: inicia no $1^{\circ}$ ano, não mais a partir do $2^{\circ}$ ano como em 1894 e segue uma trajetória também distinta, parte dos sólidos geométricos nos dois primeiros anos e somente no $3^{\circ}$ ano trabalha mais especificamente com a geometria plana.

O Decreto $2.944^{16}$ de 1918 , mesmo distante treze anos em relação ao de 1905 apresenta poucas alterações em geometria. Tanto os conteúdos de geometria propostos assim como a trajetória do ensino partindo dos sólidos geométricos para superfícies planas são mantidos. A diferença evidencia-se no $3^{\circ}$ ano em que se acrescenta: "Traçado de linhas com uso do compasso", que não havia nos programas anteriores.

As duas últimas reformas do ensino primário paulista na Primeira República, de 1921, que reduz para dois anos a duração do ensino primário e a de 1925, que restabelece a duração de quatro anos, mantém em linhas gerais a mesma estrutura do Programa de 1918. O destaque para o último programa da Primeira República, de 1925, é a nova denominação da matéria, que nos $1^{\circ}$ e $2^{\circ}$ anos primários passa ser designada por Forma e nos $3^{\circ}$ e $4^{\circ}$ anos de Geometria.

\section{Considerações Finais}

Ao analisar os programas das matérias que compõe a escola primária do Estado de São Paulo, ao longo do final do século XIX, e início do século 
$\mathrm{XX}$, com destaque para a passagem do Império para a República, pode-se dizer que a reforma da Instrução Pública que implementa a estruturação do primário em grupos escolares apresenta modificações substantivas para o tratamento da Geometria. Tais mudanças referem-se à passagem das noções elementares de geometria, para a própria Geometria como uma rubrica escolar consolidada nos programas oficiais de ensino.

No que diz respeito ao enfoque e finalidade da geometria, o seu detalhamento na legislação de 1894 deixa em aberto a metodologia a ser empregada para o programa, e, por outro lado, assegura uma proposta de curso de geometria plana completo e de conceitos centrais de geometria espacial, para além da parte métrica aplicada à geometria, o cálculo de áreas e volumes. A proposta defendida por Rui Barbosa de uma taquimetria é contemplada no $4^{\circ}$ ano do curso preliminar.

Geometria prática é a denominação empregada para a referida matéria, seja no livro de Olavo Freire como na Revista de Ensino, ambos como referências significativas de contato com os professores da rede oficial de São Paulo, como se mostra anteriormente. O significado da expressão Geometria Prática relaciona os conceitos geométricos com objetos e ferramentas da vida prática e inclui nessa praticidade as construções geométricas com régua e compasso. A incorporação dos traçados com uso de compasso nos Programas de geometria a partir de 1918 reforça a associação da habilidade no manuseio dos instrumentos de construção geométrica com a praticidade da geometria.

De acordo com o historiador André Chervel, o estudo das finalidades da escola está em estreita relação com a história das disciplinas e se inicia com a série de textos oficiais programáticos, leis, decretos, porém não se reduzem a tais documentos. $\mathrm{O}$ estudo das finalidades não pode abstrair os ensinos reais, e sim cotejar uma dupla documentação, a dos objetivos fixados e a da realidade pedagógica (1990). Os resultados apresentados nesse artigo constituem subsídios para a investigação acerca da finalidade teórica de uma "geometria prática" em confronto com as finalidades reais de uma disciplina - geometria que está nascendo nas escolas primárias do final do século XIX.

\section{Notas}

1 Este texto compõe um dos resultados parciais de desenvolvimento de projeto de pesquisa financiado pelo $\mathrm{CNPq}$ através do Edital de Ciências Humanas, 2010.

2 Trata-se do livro "Alicerces da pátria: História da escola primária no Estado de São Paulo (18901976)", publicado em 2009, originário da tese de Livre-docência de Rosa Fátima de Souza na Faculdade de Ciências e Letras da Universidade Estadual, Campus Araraquara.

3 Lei $n^{\circ} .310$ de 16 de março de 1846. Coleção das Leis da Província de São Paulo, art.1 $1^{\circ}$. Foi essa reforma que cria, pela primeira vez, na Província, a Escola Normal e institui as segundas cadeiras de primeiras letras na tentativa de elevar o nível de instrução em São Paulo (Souza, 2009, p. 45).

4 Decreto no. 7.247 , de 19 de abril de 1879 Reforma o ensino primário e secundário no município da Corte e o superior em todo o Império. Assinado por Carlos Leôncio de Carvalho. Os pareceres elaborados por Rui Barbosa, em 1882 são referentes à reforma educacional, apresentada por Leôncio de Carvalho.

5 Art. $2^{\circ}$ : Até se mostrarem habilitados em todas as disciplinas que constituem o programma das escolas primarias do $1^{\circ}$ grau, são obrigados a freqüentá-las, no município da Corte, os indivíduos de um e outro sexo, de 7 a 14 anos de idade.

$6 \mathrm{O}$ ensino nas escolas do $2^{\circ}$ grau consta da continuação e desenvolvimento das disciplinas ensinadas nas do $1^{\circ}$ grau e outras a mais.

7 Rui Barbosa apresentou ao parlamento brasileiro dois pareceres em 1882: um sobre a reforma do ensino primário e outro sobre o ensino secundário e superior. $\mathrm{O}$ parecer sobre o ensino primário intitulado "Reforma do Ensino Primário e Várias Instituições Complementares da Instrução Pública" foi apresentado ao parlamento em 12 de setembro de 1882, mas a publicação do volumoso incluindo os anexos foi concluída em 1883, data efetiva de aparecimento desse documento (Souza, 2009, p. 75).

8 Lei no. 88 de 18 de Setembro de 1892 - Reforma da Instrucção Pública do Estado. Assinada por Bernardino de Campos, presidente do Estado de São Paulo (Valente, 2010).

9 Decreto 144B de 30 de dezembro de 1892 Aprova o regulamento da Instrução Pública. Assinada por Bernardino de Campos, presidente do Estado de São Paulo (Valente, 2010).

10 Oscar Thompson e Bendito Maria Tolosa atuavam como professores na Escola Modelo 
anexa à Escola Normal e Antonio Rodrigues Alves era inspetor de ensino (Souza, 2009, p. 83).

11 Decreto 248 de 26 de julho de 1894 - Approva o regimento interno das escolas públicas. Assinada por Bernardino de Campos, presidente do Estado de São Paulo (Valente, 2010).

12 Os conteúdos são distribuídos em 4 anos do curso preliminar. Para cada ano, há ainda uma subdivisão, em $1^{\mathrm{a}}$ e $2^{\mathrm{a}}$ séries.

13 Prova da aluna Dorvalina de Moraes Rosa, $3^{\circ}$ ano, Grupo Escolar Antonio Padilha, Sorocaba, 1896 (Souza, 2009, p. 94).

14 Revista de Ensino da Associação Beneficente do Professorado Público de São Paulo. Publicação bimestral subsidiada pelo governo do Estado. O primeiro número é publicado em 1902 (Valente, 2010).

15 Decreto 1.281 de 24 de abril de 1905 - Approva e manda observar o programma de ensino para os grupos escholares e escholas modelo. Assinado por Jorge Tibiriçá - J. Cardoso de Almeida.

16 Decreto 2.944 de 08 de agosto de 1.918 Aprova o regulamento para a Execução da Lei 1.579 , de 19 de dezembro de 1917, que estabelece diversas disposições sobre a Instrução Pública do Estado. Assinado por Altino Arantes - Oscar Rodrigues Alves.

\section{Referências}

BARBOSA, R. Reforma do Ensino Primário e várias Instituições Complementares da Instrução Pública. Obras Completas. Vol. X, tomo I ao IV. Rio de Janeiro: Ministério da Educação e Saúde, 1947.

CHERVEL, A. História das disciplinas escolares: reflexões sobre um campo de pesquisa. In: Teoria \& Educação, Porto Alegre, nº. 2, 1990, p. 177-229.

COLLEÇÃO DAS LEIS DO IMPÉRIO DO
BRAZIL. Rio de Janeiro: Typographia Nacional, 1808-1889.

Acesso: http://www.camara.gov.br/Internet/InfDoc/conteudo /colecoes/Legislacao/Legimp-J_19.pdf. 12 de nov. 2011.

FREIRE, O. Primeiras Noções de Geometria Pratica. Rio de janeiro: Francisco Alves \& $C^{\text {ia }}$, 1907.

JULIA, D. A cultura escolar como objeto histórico. Revista Brasileira de História da Educação. Campinas, SP. SBHE/Editora Autores Associados. Jan./jun. no. 1, 2001.

MOACYR, P. A instrução e o Império. 10. Vol., 1936. Brasiliana Eletrônica. Acesso: http://www.brasiliana.com.br/obras/a-instrucao-e-oimperio-1-vol/pagina/181/texto. 20 de março de 2011.

SÃO PAULO (Estado). Decreto $n^{\circ} .248$, de 26 de julho de 1894. Approva o regimento interno das escolas publicas. Collecção das Leis e Decretos do Estado de São Paulo de 1894. Tomo IV. São Paulo: Typographia do Diario Official, 1918.

REVISTA de Ensino da Associação Beneficente do Professorado Público de São Paulo. São Paulo: Typographia do Diário Oficial, 1902-1904.

SOUZA, R. F. Alicerces da pátria: História da escola primária no Estado de São Paulo (18901976). Campinas, SP: Mercado de Letras, 2009.

VALENTE, W. R. (Org). A educação matemática na escola de primeiras letras 1850-1960: um inventário de fontes. São Paulo: GHEMAT/FAPESP, 2010. 1DVD. VALENTE, W. R. A geometria na escola de primeiras letras: Elementos para a história da educação matemática nos anos iniciais escolares. In: Anais da 34 Reunião Anual da ANPEd, 2011.

\section{Sobre os autores:}

Maria Célia Leme da Silva: UNIFESP - Campus Diadema.

Wagner Rodrigues Valente: UNIFESP - Campus Guarulhos. 